\title{
ANALISIS PENCEMARAN UDARA AKIBAT KEPADATAN JALAN LALU LINTAS DI KOTA PADANG (Studi Kasus: Karbon Monoksida di Jalan Prof Dr Hamka, Jalan Khatib Sulaiman, dan Jalan Rasuna Said)
}

\author{
Putri Ines Wijaya \\ Program Studi Geografi Fakultas Ilmu Sosial, \\ Universitas Negeri Padang \\ Email : putriines.wijaya@yahoo.com
}

\begin{abstract}
ABSTRAK
Penelitian ini bertujuan untuk: (1) mengetahui kepadatan kendaraan bermotor Jalan Prof. Dr. Hamka, Jalan Khatib Sulaiman, dan Jalan Rasuna Said, Kota Padang, (2) mengetahui volume karbon monoksida (CO) yang dilepaskan kendaraan bermotor yang diakibatkan oleh kepadatan Jalan Prof. Dr. Hamka, Jalan Khatib Sulaiman, dan Jalan Rasuna Said, Kota Padang.

Jenis penelitian ini adalah deskriptif kuantitatif dengan menggunakan data primer untuk melihat volume kendaraan, kadar karbon monoksida (CO), dan meteorologi. Data yang diperoleh di lapangan diolah dengan menggunakan rumus dari Interval untuk jumlah kendaraan, rumus ISPU (Indeks Standar Pencemaran Udara) untuk karbon monoksida (CO) di udara.

Hasil penelitian menemukan bahwa, (1) kepadatan tertinggi terjadi di ruas Jalan Khatib Sulaiman dihari Senin total jumlah kendaraan 13125 unit kendaraan dengan lebar ruas jalan 3,50 meter. Kepadatan terendah di hari Sabtu di ruas Jalan Khatib Sulaiman total jumlah kendaraan 3826 unit kendaraan (2) konsentrasi gas CO tertinggi di Jalan Prof. Dr. Hamka sebesar 160,66 mg/m $\mathrm{m}^{3}$ kategori udara tidak sehat, sedangkan konsentrasi terendah di Jalan Rasuna Said sebesar $26,67 \mathrm{mg} / \mathrm{m}^{3}$ kategori udara belum tercemar.
\end{abstract}

Kata kunci : kepadatan lalu lintas, pencemaran udara, karbon monoksida (CO)

\section{ABSTRACT}

His study aims to: (1) know the density of motor vehicles Road Prof. Dr. Hamka, Jalan Khatib Sulaiman, and Jalan Rasuna Said, Kota Padang, (2) to know the volume of carbon monoxide (CO) released by motor vehicles caused by the density of Prof. Roads. Dr. Hamka, Jalan Khatib Sulaiman, and Jalan Rasuna Said, Padang City.

The type of this research is descriptive quantitative by using primary data to see vehicle volume, carbon monoxide (CO), and meteorology. The data obtained in the field is processed using the formula of the Interval for the number of vehicles, the formula of the ISPU (Air Pollution Standard Index) for carbon monoxide $(\mathrm{CO})$ in the air.

The results found that, (1) the highest density occurred in Jalan Khatib Sulaiman Street on Monday total vehicle number 13125 units of vehicles with road width of 3.50 meters. The lowest density on Saturdays in Jalan Khatib Sulaiman total number of vehicles of 3826 units of vehicles (2) the highest CO gas concentration on Jalan Prof. Dr. Hamka of $160.66 \mathrm{mg} / \mathrm{m}^{3}$ unhealthy air category, while the lowest concentration in Jalan Rasuna Said of $26.67 \mathrm{mg} / \mathrm{m}^{3}$ air category has not been contaminated.

Keywords: traffic density, air pollution, carbon monoxide (CO)

\footnotetext{
${ }^{1}$ Artikel ini ditulis dari skripsi penulis dengan judul Analisis Pencemaran Udara Akibat Kepadatan Jalan Lalu Lintas Di Kota Padang, periode Maret 2018
} 


\section{PENDAHULUAN}

Bertambahnya pemakaian kendaraan tiap tahun pada data Badan Pusat Statistik tahun 2014 sehingga pemakaian bahan bakar juga meningkat. Penggunaan bahan bakar minyak yang dipergunakan sebagai penggerak bagi kendaraan, sistem ventilasi mesin dan yang terutama adalah buangan dari knalpot hasil pembakaran bahan bakar yang merupakan pencampuran ratusan gas dan aerosol menjadi penyebab utama keluarnya berbagai pencemar.

Kepadatan lalu lintas terjadi bila pada kondisi lalu lintas di jalan raya mulai tidak stabil, kecepatan operasi menurun relatif cepat akibat adanya hambatan yang timbul dan kebebasan bergerak relatif kecil (Sumadi, 2006). Lalu lintas tergantung pada kapasitas jalan, dimana banyaknya kendaraan yang ingin bergerak tetapi kalau

kapasitas jalannya tidak bisa menampung maka lalu lintas yang ada akan terhambat (Sinulingga, 1999).

Tidak seimbangnya pertambahan jumlah kendaraan dengan sarana jalan yang tersedia, mengakibatkan pada beberapa ruas jalan yang menjadi jalur utama kendaraan umum di kota-kota terjadi kemacetan, terutama pada jamjam sibuk.

Emisi CO di Padang-pun dapat meningkat karena kebutuhan masyarakat kota Padang dalam menjalankan aktifitas sehari-hari sangat tinggi. Salah satunya adalah tranportasi untuk menjalankan mobilitas seharihari, saat ini masyarakat kota Padang lebih memilih memakai kendaraan pribadi dari pada memakai angkutan umum untuk menjalankan aktifitasnya.
Hal ini mengakibatkan pertumbuhan populasi kendaraan di jalan raya yang tinggi.

Efek dari pertumbuhan ini adalah kepadatan jalan raya yang tinggi dan membuat macet di mana-mana. Penduduk Kota Padang telah mencapai 902,413 jiwa dengan luas wilayah 694,96 km² (BPS Kota Padang, Kota Padang Dalam Angka, 2016).

Ruas-ruas Jalan Prof. Dr. Hamka, Jalan Khatib Sulaiman, dan Jalan Rasuna Said merupakan ruas jalan yang padat di Kota Padang karena terdapat beragam aktivitas, seperti pusat pebelanjaan, pusat perkantoran, pusat kota dan perdagangan. Jalan Prof. Dr. Hamka, Jalan Khatib Sulaiman, dan Jalan Rasuna Said terdapat tiga ruas jalan yaitu Jalan Hamka, Jalan Khatib Sulaiman, dan Jalan Rasuna Said, yang mempunyai karakteristik aktivitas masing-masing.

Hal ini menyebabkan mobilitas perjalanan ke ruas jalan tersebut menjadi tinggi sehingga dapat memicu terjadinya permasalahan lalu lintas. Permasalan yang utama adalah meningkatnya pengguna kendaraan bermotor yang menyebabkan terjadi kemacetan pada beberapa ruas Jalan Prof. Dr. Hamka, Jalan Khatib Sulaiman, dan Jalan Rasuna Said

Kepadatan lalu lintas di Kota Padang dari hari ke hari semakin bertambah, terlebih pada setiap akhir pekan. Kenyamanan kota Padang sudah tidak dapat dirasakan lagi seperti pada masa lalu, terutama di kawasankawasan dengan aktivitas tinggi, seperti kawasan jalan Prof Dr. Hamka (depan Basko Hotel). 
Banyaknya kendaraan bermotor yang lewat dan berhenti, menyebabkan kawasan tersebut menjadi sesak dan sempit. Sering terjadinya kemacetan disebabkan tingginya tingkat pengguna lalu lintas yang berinteraksi pada ruas-ruas Jalan Prof. Dr. Hamka, Jalan Khatib Sulaiman, dan Jalan Rasuna Said juga menyebabkan kemacetan terjadi hampir sepanjang hari terutama pada pagi dan sore hari yang merupakan jam-jam sibuk.

Adapun permasalahan yang akan diteliti yaitu berapa banyak karbon monoksida yang berada di titik-titik kemacetan di Kota Padang pada lokasi penelitian, peneliti hanya mengambil tiga titik lokasi kemacetan yang masing-masing fungsi jalannya yaitu, pertama sepanjang Jalan Prof. Dr. Hamka dengan fungsi jalan arteri sekunder, kedua berada di Jalan Khatib Sulaiman dengan fungsi jalan arteri sekunder, dan Jalan Rasuna Said dengan fungsi jalan arteri primer. Sehubungan dengan hal tersebut, maka penulis tertarik untuk mengakaji lebih lanjut mengenai "Analisis Pencemaran Udara Akibat Kepadatan Jalan Lalu Lintas di Kota Padang”.

\section{METODE PENELITIAN}

Jenis penelitian ini adalah penelitian kuantitatif untuk menentukan konsentrasi polutan akibat emisi kendaraan bermotor di udara. Metode yang dipergunakan dalam penelitian kuantitatif khusunya kuantitatif analitik adalah metode dedutif, dalam metoda ini teori ilmiah yang telah diterima kebenarannya dijadikan acuan dalam mencari kebenaran selanjutnya.
Waktu penelitian di laksanakan selama 9 hari, yaitu dari tanggal 13 November sampai dengan 3 Desember 2017. Survey dilakukan pada hari Senin, Rabu, dan Minggu, dengan asumsi bahwa Senin dan Rabu mewakili hari sibuk sementara Sabtu adalah hari libur.

Penelitian yang dianjurkan untuk mengukur volume kendaraan saat hari sibuk yaitu hari Senin - Jumat, dan untuk mengukur volume kendaraan saat hari libur pada hari Sabtu dan Minggu (Dinas Perhubungan Angkutan Kota). Pengukuran dilakukan pada interval waktu pada pukul 06:00 - 09:00 WIB, hal ini mengacu pada Peraturan Menteri Lingkungan Hidup no.12 tahun 2010 tentang pelaksanaan pengendalian pencemaran udara di daerah, bisa dilihat pada gambar 1:

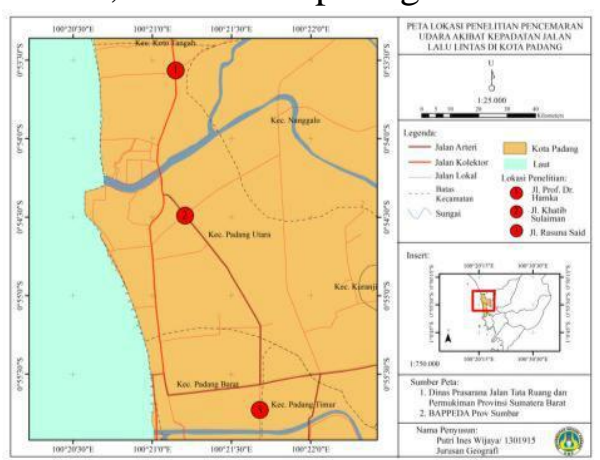

Gambar 1 : Peta Lokasi Penelitian

Penelitian ini pengumpulan data dilakukan pada Jalan Prof. Dr. Hamka, Jalam Khatib Sulaiman, dan Jalan Rasuna Said, ditempatkan di 3 titik pengamatan yaitu di Jalan Simpang Tunggul Hitam, Jalan Simpang Presiden, dan Jalan Rasuna Said.

Sample dalam penelitian ini digunakan untuk mengetahui pencemaran udara akibat kemacetan saja. Teknik pengambilan sampel pada penelitian ini yaitu menggunakan cara 
purposive sampling yaitu pengambilan sampel dilakukan secara sengaja dan telah sesuai dengan semua persyaratan yang diperlukan. Jenis kendaraan yang dihitung pada pengukuran jumlah kendaraan berdasarkan jenis yaitu mobil, bus, dan kendaraan motor.

Pengukuran jumlah kendaraan berdasarkan bahan bakar yang digunakan terdiri dari bensin, dikarenakan oleh kendaraan berat tidak melewati jalan di lokasi penelitian. Penelitian dilakukan pada hari Senin,

Rabu, dan Sabtu, sehingga membutuhkan waktu selama 9 hari untuk ketiga lokasi penelitian.
Pemilihan lokasi ini dilakukan karena di ketiga jalan termasuk kedalam 10 jalan dengan kepadatan tertinggi di Kota Padang menurut Dinas Perhubungan tahun 2013. Faktor pohon pelindung disepanjang jalan juga mempengaruhi pemilihan lokasi penelitian, dengan adanya perbedaan banyaknya pohon pelindung disepanjang jalan akan mempengaruhi hasil dari pencemaran udara disekitarnya menurut Dinas Lingkungan Hidup.

Jenis teknik pengumpulan data yang diperlukan dapat dilihat pada tabel 1 :

Tabel 1

Jenis dan Teknik Pengumpulan Data

\begin{tabular}{|l|l|c|c|}
\hline No & \multicolumn{1}{|c|}{ Jenis Data } & Teknik & Kengumpulan Data \\
\hline 1. & Ruas jalan & Sekunder & Dinas PU \\
\hline 2. & Panjang ruas jalan & Sekunder & Dinas PU \\
\hline 3. & Ruas jalan yang padat kendaraan & Primer & Survey \\
\hline 4. & Volume kendaraan & Primer & Survey \\
\hline 5. & Karbon monoksida & Primer & Survey \\
\hline 6. & Meteorologi & Primer & Survey \\
\hline
\end{tabular}

Sumber: Hasil Analisis, 2017

Teknis Analisis hasil perhitungan langsung kendaraan dilapangan secara manual sehingga jumlah kendaraan yang diketahui dibutuhkan interval untuk menentukan tingkat kepadatan tersebut. Besar kelas interval berdasarkan metode yang digunakan oleh Suprapto Dibyosaputro (1999) dalam Tjahjono (2007) adalah:

Keterangan:

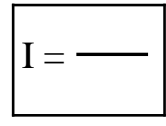

I : Besar Kelas Interval

$\mathrm{C}$ : Jumlah kendaraan tertinggi

$\mathrm{K}$ : Jumlah kendaraan terendah
$\mathrm{K}_{\mathrm{I}}$ : Jumlah Waktu Pengukuran

Perhitungan karbon monoksida menurut Indeks Standar Pencemaran Udara (ISPU) menurut keputusan Kepala Badan Pengendalian Dampak Lingkungan No. 107 tahun 1997 tanggal 21 november 1997. Dapat dilihat pada rumus berikut:

ISPU $=\longrightarrow($

Keterangan:

I : ISPU terhitung

: ISPU batas atas

: ISPU batas bawah 
: Ambien batas atas

: Ambien batas bawah

: Kadar ambien nyata hasil pengukuran

Apabila satuan hasil pengukuran parameter CO dalam satuan ppm, dirubah menjadi $\mathrm{mg} / \mathrm{m}^{3}$ menurut Indeks Standar Pencemaran Udara (ISPU), menggunakan rumus:

Keterangan:

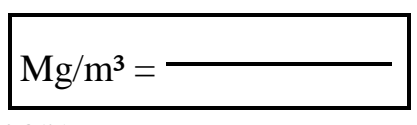

$\mathrm{Mg} / \mathrm{m}^{3}$ : Bagian uap atau gas per sejuta bagian volume udara

$\mathrm{N}$ (ppm) : Jumlah kadar CO dalam ppm

$\mathrm{BM}$ : Berat Molekul $(\mathrm{C}=12 ; \mathrm{O}=16)$

24,45 : Volume Molar

Perhitungan dan pelaporan serta informasi Indeks Standar Pencemar Udara ditetapkan oleh Kepala Badan Pengendalian Dampak Lingkungan, yaitu Keputusan Kepala Badan Pengendalian Dampak Lingkungan No. 107 Tahun 1997 Tanggal 21 November 1997. Keputusan Kepala Badan Pengendalian Dampak Lingkungan, memuat diantaranya adalah :

a. Batas Indeks Standar Pencemar Udara Dalam Satuan SI
Hasil dari pengambilan sampling $\mathrm{CO}$ yang sudah dalam satuan $\mathrm{mg} /$ akan ditentukan termasuk kedalam batas ISPU (Indeks Standar Pencemaran Udara) yang ada, nantinya ditentukan batas atas, batas bawah, ambien batas atas, dan ambien batas bawah. Berikut batas ISPU bisa dilihat pada tabel 2 berikut:

Tabel 2

Batas Indeks Standar Pencemar Udara Dalam Satuan SI

\begin{tabular}{|c|c|}
\hline ISPU & $\begin{array}{c}\text { Ambien } \\
\mathbf{C O} \\
\mathbf{m g} /\end{array}$ \\
\hline 50 & 5 \\
\hline 100 & 10 \\
\hline 200 & 17 \\
\hline 300 & 34 \\
\hline 400 & 46 \\
\hline 500 & 57.5 \\
\hline
\end{tabular}

Sumber : Dinas Lingkungan Hidup

Provinsi Sumatera Barat

b. Pengaruh Indeks Standar Pencemar Udara untuk setiap Parameter pencemar

Hasil dari perhitungan menggunakan rumus ISPU (Indeks Standar Pencemaran Udara), termasuk kedalam rentang dan kategori yang selengkapnya dapat dilihat pada tabel 3 berikut:

Tabel 3

Pengaruh Indeks Standar Pencemar Udara Parameter Pencemar

\begin{tabular}{|c|c|l|}
\hline Kategori & Rentang & \multicolumn{1}{c|}{ Carbon Monoksida (CO) } \\
\hline Baik & $1-50$ & Tidak ada efek \\
\hline Sedang & $51-100$ & Perubahan kimia darah tapi tidak terdeteksi \\
\hline Tidak Sehat & $101-199$ & $\begin{array}{l}\text { Peningkatan pada kardiovaskular pada } \\
\text { perokok yang sakit jantung }\end{array}$ \\
\hline $\begin{array}{c}\text { Sangat Tidak } \\
\text { Sehat }\end{array}$ & $\begin{array}{l}\text { Meningkatnya kardiovaskular pada perokok } \\
\text { yang sakit jantung dan akan tampak } \\
\text { beberapa kelemahan yang terlihat secara } \\
\text { nyata }\end{array}$ \\
\hline Berbahaya & $300-299$ Lebih & $\begin{array}{l}\text { Tingkat yang berbahaya bagi semua } \\
\text { populasi yang terpapar }\end{array}$ \\
\hline
\end{tabular}

Sumber: Dinas Lingkungan Hidup Provinsi Sumatera Barat 
Pada tabel tersebut bisa dilihat bahwa rentang angka dalam kategori udara yang masih belum tercemar yaitu rentang 1 - 100, bila hasil perhitungan ISPU melewati rentang 100 maka, udara sudah tercemar.

\section{HASIL DAN PEMBAHASAN}

Kota Padang adalah ibukota Provinsi Sumatera Barat yang terletak di pantai barat Pulau Sumatera dan berada pada koordinat $0^{\circ} 44^{\prime} 00^{\prime \prime}$ LS $1^{\circ} 08^{\prime} 35^{\prime \prime} \mathrm{LS}$ dan $100^{\circ} 05^{\prime} 05^{\prime \prime} \mathrm{BT}$ $100^{\circ} 34^{\prime} 09^{\prime}$ BT. Kecamatan Padang
Utara dan Kecamatan Padang Selatan merupakan lokasi titik penelitian, yang tepatnya Kecamatan Padang Utara di Jalan Prof. Dr. Hamka, Jalan Khatib Sulaiman, dan Kecamatan Padang Selatan berada di Jalan Rasuna Said. Berdasarkan data dari Dinas Prasarana Tata Ruang dan Permukiman, didapat informasi tentang jenis jalan di Kota padang berdasarkan ruas jalan, untuk lebih jelasnya dapat dilihat pada tabel 4 berikut ini:

Tabel 4

Jenis Jalan Berdasarkan Klasifikasi/ Ruas Jalan di Kota Padang

\begin{tabular}{|c|l|c|c|c|}
\hline No & Nama Jalan & $\begin{array}{c}\text { Lebar Ruas } \\
\text { Jalan }(\mathbf{m})\end{array}$ & Tipe Ruas & Jenis Jalan \\
\hline 1. & $\begin{array}{l}\text { Jl. Prof. Dr. } \\
\text { Hamka }\end{array}$ & 3.00 & $\begin{array}{c}\text { 4 lajur terbagi/ 1 } \\
\text { arah }\end{array}$ & $\begin{array}{c}\text { Arteri } \\
\text { Sekunder }\end{array}$ \\
\hline 2. & $\begin{array}{l}\text { Jl. Khatib } \\
\text { Sulaiman }\end{array}$ & 3.50 & $\begin{array}{c}\text { 4 lajur terbagi/ 1 } \\
\text { arah }\end{array}$ & $\begin{array}{c}\text { Arteri } \\
\text { Sekunder }\end{array}$ \\
\hline 3. & Jl. Rasuna Said & 3.50 & $\begin{array}{c}\text { 4 lajur tak } \\
\text { terbagi }\end{array}$ & $\begin{array}{c}\text { Arteri } \\
\text { Primer }\end{array}$ \\
\hline
\end{tabular}

Sumber : Dinas Prasjal Tarkim Prov Sumbar

\section{Kepadatan Kendaraan}

Hasil penelitian yang dilakukan pada hari Senin, Rabu, dan Sabtu tanggal 13 November 2017 - 03 Desember 2017 di Jalan Prof. Dr. Hamka yang berada di Jalan Simpang Tunggul Hitam, Jalan Khatib Sulaiman yang berada di Jalan Simpang Presiden, dan Jalan Rasuna Said. Menghitung kendaraan yang melewati lokasi penelitian yaitu menggunakan alat Counter. Volume kendaraan dibedakan berdasarkan jenis kendaraan yaitu motor, mobil penumpang, dan bus, bisa dilihat pada tabel 5 berikut: 
Tabel 5

Volume Kendaraan di ruas Jalan Prof. Dr. Hamka, Jalan Khatib Sulaiman, dan Jalan Rasuna Said Kota Padang

\begin{tabular}{|c|c|c|c|c|c|c|c|c|}
\hline \multirow[t]{2}{*}{ No } & \multirow[t]{2}{*}{ Nama Jalan } & \multirow[t]{2}{*}{ Hari } & \multirow[t]{2}{*}{$\begin{array}{c}\text { Waktu } \\
\text { Pengambilan }\end{array}$} & \multicolumn{3}{|c|}{$\begin{array}{c}\text { Volume Kendaraan } \\
\text { (Unit) }\end{array}$} & \multirow{2}{*}{$\begin{array}{c}\text { Jumlah } \\
\text { Kendaraan } \\
\text { /jam (Unit) }\end{array}$} & \multirow{2}{*}{$\begin{array}{l}\text { Total Jumlah } \\
\text { Kendaraan } \\
\text { /hari (Unit) }\end{array}$} \\
\hline & & & & Motor & Mobil & $\overline{\text { Bus }}$ & & \\
\hline \multirow{9}{*}{1.} & \multirow{9}{*}{$\begin{array}{l}\text { Jl. Prof. } \\
\text { Hamka }\end{array}$} & \multirow{3}{*}{ Senin } & $06.00-07.00$ & 2156 & 982 & 21 & 3159 & \multirow{3}{*}{12394} \\
\hline & & & $07.01-08.00$ & 3370 & 1736 & 18 & 5124 & \\
\hline & & & $08.01-09.00$ & 2784 & 1315 & 12 & 4111 & \\
\hline & & \multirow{3}{*}{ Rabu } & $06.00-07.00$ & 1372 & 683 & 12 & 2067 & \multirow{3}{*}{7948} \\
\hline & & & $07.01-08.00$ & 2511 & 1494 & 15 & 4020 & \\
\hline & & & $08.01-09.00$ & 1028 & 822 & 11 & 1861 & \\
\hline & & \multirow{3}{*}{ Sabtu } & $06.00-07.00$ & 628 & 439 & 10 & 1077 & \multirow{3}{*}{5029} \\
\hline & & & $07.01-08.00$ & 1416 & 923 & 13 & 2352 & \\
\hline & & & $08.01-09.00$ & 985 & 604 & 11 & 1600 & \\
\hline \multirow{9}{*}{2.} & \multirow{9}{*}{$\begin{array}{c}\text { Jl. KH } \\
\text { Sulaiman }\end{array}$} & \multirow{3}{*}{ Senin } & $06.00-07.00$ & 2058 & 834 & 13 & 2905 & \multirow{3}{*}{13125} \\
\hline & & & $07.01-08.00$ & 3862 & 2326 & 15 & 6203 & \\
\hline & & & $08.01-09.00$ & 2374 & 1631 & 12 & 4017 & \\
\hline & & \multirow{3}{*}{ Rabu } & $06.00-07.00$ & 673 & 492 & 13 & 1178 & \multirow{3}{*}{6549} \\
\hline & & & $07.01-08.00$ & 1859 & 1204 & 9 & 3072 & \\
\hline & & & $08.01-09.00$ & 1472 & 816 & 11 & 2299 & \\
\hline & & \multirow{3}{*}{ Sabtu } & $06.00-07.00$ & 584 & 379 & 12 & 975 & \multirow{3}{*}{3826} \\
\hline & & & $07.01-08.00$ & 928 & 663 & 13 & 1604 & \\
\hline & & & $08.01-09.00$ & 741 & 496 & 10 & 1247 & \\
\hline \multirow{9}{*}{3.} & \multirow{9}{*}{$\begin{array}{l}\text { Jl. Rasuna } \\
\text { Said }\end{array}$} & \multirow{3}{*}{ Senin } & $06.00-07.00$ & 1847 & 851 & 11 & 2709 & \multirow{3}{*}{9868} \\
\hline & & & $07.01-08.00$ & 2616 & 1473 & 16 & 4105 & \\
\hline & & & $08.01-09.00$ & 2083 & 958 & 13 & 3054 & \\
\hline & & \multirow{3}{*}{ Rabu } & $06.00-07.00$ & 1194 & 493 & 12 & 1699 & \multirow{3}{*}{8972} \\
\hline & & & $07.01-08.00$ & 2404 & 1876 & 14 & 4294 & \\
\hline & & & $08.01-09.00$ & 1705 & 1264 & 10 & 2979 & \\
\hline & & \multirow{3}{*}{ Sabtu } & $06.00-07.00$ & 1075 & 446 & 11 & 1532 & \\
\hline & & & $07.01-08.00$ & 1361 & 812 & 14 & 2187 & 7332 \\
\hline & & & $08.01-09.00$ & 2301 & 1299 & 13 & 3613 & \\
\hline & & & & & & & Total Jumlah & 75043 \\
\hline
\end{tabular}

Sumber : Pengambilan Langsung pada Bulan November 2017

Dari tabel tersebut dibutuhkan jumlah kendaraan tiap jam untuk mengetahui tingkat kepadatan kendaraan, sebelum mengetahui tingkat kendaraan terlebih dahulu menentukan interval dari kendaraan dengan metode dari Suprapto Dibyosaputro (1998). Mengetahui kepadatan kendaraan perhari dibutuhkan jumlah kendaraan ditiap jam, bisa dilihat pada pada tabel 6 berikut ini: 
Tabel 6

Kelas Interval di Kepadatan Jalan Prof. Dr. Hamka, Jalan Khatib Sulaiman, dan Jalan Rasuna Said Kota Padang

\begin{tabular}{|c|c|c|}
\hline $\mathrm{I}=\mathrm{C}-\mathrm{K} / \mathrm{Ki}$ & Interval & Keterangan \\
\hline \multirow{3}{*}{3099} & $3826-6925$ & Rendah \\
\cline { 2 - 3 } & $6925-10024$ & Sedang \\
\cline { 2 - 3 } & $10024-13123$ & Tinggi \\
\hline
\end{tabular}

Sumber : Hasil Analisis, 2017

Pada tabel 6 range yang didapat untuk menentukan interval sebesar 3099, hasil penambahan jumlah kendaraan terendah dengan jumlah range didapatkan intervalnya, dari interval tersebut ditentukan tingkat kepadatan menurut total jumlah kendaraan. Bisa dilihat pada tabel 7:

\section{Tabel 7}

Kepadatan Lalu Lintas di ruas Jalan Prof. Dr. Hamka, Jalan Khatib Sulaiman, dan Jalan Rasuna Said Kota Padang

\begin{tabular}{|l|l|l|r|c|}
\hline No & Nama Jalan & Hari & $\begin{array}{c}\text { Total Jumlah } \\
\text { Kendaraan }\end{array}$ & $\begin{array}{c}\text { Kepadatan } \\
\text { /hari }\end{array}$ \\
\hline 1. & \multirow{2}{*}{ Jl. Prof. Hamka } & Senin & 12394 & Tinggi \\
\cline { 4 - 5 } & & Rabu & 7948 & Sedang \\
\cline { 3 - 5 } & & Sabtu & 5029 & Rendah \\
\hline 2. & \multirow{2}{*}{ Jl. KH Sulaiman } & Senin & 13125 & Tinggi \\
\cline { 4 - 5 } & & Rabu & 6549 & Rendah \\
\cline { 3 - 5 } & & Sabtu & 3826 & Rendah \\
\hline 3. & \multirow{2}{*}{ Jl. Rasuna Said } & Senin & 9868 & Tinggi \\
\cline { 3 - 5 } & & Rabu & 8972 & Sedang \\
\cline { 3 - 5 } & & Sabtu & 7332 & Rendah \\
\hline
\end{tabular}

Sumber : Pengambilan Langsung pada Bulan November 2017

Pada tabel 7 tersebut dapat dilihat bahwa kepadatan tertinggi terjadi dihari Senin di ruas Jalan Khatib Sulaiman dengan total jumlah kendaraan sebesar 13125 unit kendaraan yang melewati jalan tersebut saat pagi dari jam $06.00-$ 09.00 WIB, degan lebar ruas jalan yaitu 3,50 meter dan tipe ruas 4 lajur terbagi/1 arah sehingga bisa dilewati tiga mobil di satu jalur yang memiliki pembatas jalan. Kepadatan terendah terjadi dihari Sabtu di ruas Jalan Khatib Sulaiman dengan total jumlah kendaraan sebesar 3826 unit kendaraan yang melewati jalan tersebut saat pagi jam 06.00 - 09.00 WIB, degan lebar ruas jalan yaitu 3,50 meter dan tipe ruas 4 lajur terbagi/1 arah sehingga bisa dilewati tiga mobil di satu jalur dengan adanya pembatas jalan.

\section{Konsentrasi Gas Karbon Monoksida (CO) dari Odalog}

Kondisi meteorologi merupakan salah satu faktor yang berpengaruh dalam pengukuran kualitas udara ambien. Kondisi meteorologi sangat mempengaruhi besaran konsentrasi gas CO di lokasi pengukuran. Kondisi meteorologi yang diukur ketika pengukuran di lapangan meliputi: arah 
dan kecepatan angin $(\mathrm{m} / \mathrm{s})$, dan temperatur udara $\left({ }^{\circ} \mathrm{C}\right)$. Arah angin dominan ketika pengukuran di lapangan berasal dari barat, pada pagi hari, berikut data meteorologi selama sampling berlangsung dapat dilihat pada tabel 8 berikut:

\section{Tabel 8}

Data Kondisi Meteorologi Lokasi Sampling

\begin{tabular}{|c|c|c|c|c|c|c|c|}
\hline \multirow[b]{2}{*}{ No } & Nama & \multirow[b]{2}{*}{ Hari } & \multirow[b]{2}{*}{ Waktu } & \multicolumn{4}{|c|}{ Parameter Meteorologi } \\
\hline & Jalan & & & $\begin{array}{l}\text { Suhu } \\
\left({ }^{\circ} \mathbf{C}\right)\end{array}$ & $\begin{array}{c}\text { Kec. Angin } \\
(\mathrm{m} / \mathrm{s})\end{array}$ & Arah Angin & Keterangan \\
\hline \multirow[t]{9}{*}{1.} & \multirow{9}{*}{$\begin{array}{l}\text { Jl. Prof. } \\
\text { Hamka }\end{array}$} & \multirow{3}{*}{ Senin } & $06.00-07.00$ & 26 & 0 & Barat Laut & Cerah \\
\hline & & & $07.01-08.00$ & 31 & 3 & Barat Laut & Cerah \\
\hline & & & $08.01-09.00$ & 32 & 5 & Barat Laut & Cerah \\
\hline & & \multirow{3}{*}{ Rabu } & $06.00-07.00$ & 27 & 0 & Barat Laut & Berawan \\
\hline & & & $07.01-08.00$ & 29 & 2 & Barat Laut & Cerah \\
\hline & & & $08.01-09.00$ & 31 & 5 & Barat Laut & Cerah \\
\hline & & \multirow{3}{*}{ Sabtu } & $06.00-07.00$ & 26 & 0 & Barat Laut & Berawan \\
\hline & & & $07.01-08.00$ & 30 & 3 & Barat Laut & Cerah \\
\hline & & & $08.01-09.00$ & 32 & 6 & Barat Laut & Cerah \\
\hline \multirow[t]{9}{*}{2.} & \multirow{9}{*}{$\begin{array}{c}\text { Jl. KH } \\
\text { Sulaiman }\end{array}$} & \multirow{3}{*}{ Senin } & $06.00-07.00$ & 25 & 0 & Barat & Berawan \\
\hline & & & $07.01-08.00$ & 28 & 3 & Barat & Cerah \\
\hline & & & $08.01-09.00$ & 32 & 4 & Barat & Cerah \\
\hline & & \multirow{3}{*}{ Rabu } & $06.00-07.00$ & 27 & 0 & Barat & Berawan \\
\hline & & & $07.01-08.00$ & 29 & 3 & Barat & Cerah \\
\hline & & & $08.01-09.00$ & 32 & 5 & Barat & Cerah \\
\hline & & \multirow{3}{*}{ Sabtu } & $06.00-07.00$ & 27 & 0 & Barat & Cerah \\
\hline & & & $07.01-08.00$ & 28 & 2 & Barat & Cerah \\
\hline & & & $08.01-09.00$ & 31 & 6 & Barat & Cerah \\
\hline \multirow[t]{9}{*}{3.} & \multirow{9}{*}{$\begin{array}{c}\text { Jl. Rasuna } \\
\text { Said }\end{array}$} & \multirow{3}{*}{ Senin } & $06.00-07.00$ & 27 & 0 & Barat Daya & Cerah \\
\hline & & & $07.01-08.00$ & 30 & 4 & Barat Daya & Cerah \\
\hline & & & $08.01-09.00$ & 33 & 7 & Barat Daya & Cerah \\
\hline & & \multirow{3}{*}{ Rabu } & $06.00-07.00$ & 25 & 0 & Barat Daya & Berawan \\
\hline & & & $07.01-08.00$ & 27 & 2 & Barat Daya & Berawan \\
\hline & & & $08.01-09.00$ & 30 & 4 & Barat Daya & Berawan \\
\hline & & \multirow{3}{*}{ Sabtu } & $06.00-07.00$ & 27 & 0 & Barat Daya & Berawan \\
\hline & & & $07.01-08.00$ & 32 & 3 & Barat Daya & Cerah \\
\hline & & & $08.01-09.00$ & 33 & 6 & Barat Daya & Cerah \\
\hline
\end{tabular}

Sumber: Pengambilan Langsung pada bulan November 2017

Pada tabel 8 dapat dilihat bahwa suhu rata-rata lokasi sampling berkisar antara $25^{\circ} \mathrm{C}-33^{\circ} \mathrm{C}$, terjadinya kenaikan temperatur mengakibatkan penurunan tekanan udara, sehingga mempengaruhi arah angin dan kecepatan udara. Berdasarkan hasil meteorologi di atas, menunjukkan adanya hubungan antara temperatur, arah angin, untuk kecepatan angin serta arah angin dominan.

Setiap lokasi sampling memiliki hasil yang relatif sama, karena topografi dari masing-masing lokasi sampling tidak jauh berbeda, hal ini terlihat dari 
ketinggian masing-masing lokasi sampling rata-rata $\pm 2-10 \mathrm{~m}$ di atas permukaan laut, bisa dilihat pada tabel 9:

Tabel 9

Data Kadar Ambien CO di Tiga Titik Sampling

\begin{tabular}{|c|c|c|c|c|c|c|c|}
\hline No & Nama Jalan & Hari & Waktu & $\begin{array}{c}\text { Pengukuran } \\
\text { CO (ppm) }\end{array}$ & $\begin{array}{c}\mathrm{CO} \\
\left(\mathrm{mg} / \mathrm{m}^{3}\right)\end{array}$ & ISPU & Kualitas Udara \\
\hline \multirow[t]{9}{*}{1.} & \multirow{9}{*}{$\begin{array}{c}\text { J1. Prof. Dr. } \\
\text { Hamka }\end{array}$} & \multirow{3}{*}{ Senin } & $06.00-07.00$ & 5 & 5.72 & 50 & Baik \\
\hline & & & $07.01-08.00$ & 25 & 28.62 & 247 & Sangat tidak sehat \\
\hline & & & $08.01-09.00$ & 16 & 16.32 & 185 & Tidak sehat \\
\hline & & \multirow{3}{*}{ Rabu } & $06.00-07.00$ & 3 & 3.43 & 30 & Baik \\
\hline & & & $07.01-08.00$ & 16 & 18.3 & 194 & Tidak sehat \\
\hline & & & $08.01-09.00$ & 8 & 6.87 & 80 & Sedang \\
\hline & & \multirow{3}{*}{ Sabtu } & $06.00-07.00$ & 2 & 2.29 & 20 & Baik \\
\hline & & & $07.01-08.00$ & 9 & 10.3 & 90 & Sedang \\
\hline & & & $08.01-09.00$ & 6 & 6.87 & 60 & Sedang \\
\hline \multirow[t]{9}{*}{2.} & \multirow{9}{*}{$\begin{array}{c}\text { Jl. KH } \\
\text { Sulaiman }\end{array}$} & \multirow{3}{*}{ Senin } & $06.00-07.00$ & 6 & 6.87 & 60 & Sedang \\
\hline & & & $07.01-08.00$ & 21 & 24.04 & 223 & Sangat tidak sehat \\
\hline & & & $08.01-09.00$ & 13 & 14.88 & 142 & Tidak sehat \\
\hline & & \multirow{3}{*}{ Rabu } & $06.00-07.00$ & 2 & 2.29 & 20 & Baik \\
\hline & & & $07.01-08.00$ & 14 & 16.03 & 57.14 & Sedang \\
\hline & & & $08.01-09.00$ & 8 & 9.16 & 80 & Sedang \\
\hline & & \multirow{3}{*}{ Sabtu } & $06.00-07.00$ & 2 & 2.29 & 20 & Baik \\
\hline & & & $07.01-08.00$ & 8 & 9.16 & 80 & Sedang \\
\hline & & & $08.01-09.00$ & 6 & 6.87 & 60 & Sedang \\
\hline \multirow[t]{9}{*}{3.} & \multirow{9}{*}{$\begin{array}{c}\text { Jln. Rasuna } \\
\text { Said }\end{array}$} & \multirow{3}{*}{ Senin } & $06.00-07.00$ & 4 & 4.58 & 40 & Baik \\
\hline & & & $07.01-08.00$ & 12 & 13.74 & 128 & Tidak sehat \\
\hline & & & $08.01-09.00$ & 5 & 5.72 & 50 & Baik \\
\hline & & \multirow{3}{*}{ Rabu } & $06.00-07.00$ & 0 & 0 & 0 & Baik \\
\hline & & & $07.01-08.00$ & 8 & 9.16 & 80 & Sedang \\
\hline & & & $08.01-09.00$ & 4 & 4.58 & 40 & Baik \\
\hline & & \multirow{3}{*}{ Sabtu } & $06.00-07.00$ & 1 & 1.14 & 10 & Baik \\
\hline & & & $07.01-08.00$ & 4 & 4.58 & 40 & Baik \\
\hline & & & $08.01-09.00$ & 3 & 3.43 & 30 & Baik \\
\hline
\end{tabular}

Sumber: Pengambilan Langsung pada Bulan November 2017 
Banyak pohon pelindung disepanjang jalan lokasi penelitian mempengaruhi pencemaran udara dari gas CO akibat hasil pembakaran mesin kendaraan bermotor. Berikut tabel 10 jumlah pohon pelindung jalan di lokasi penelitian:

\section{Tabel 10}

Jumlah Pohon di Jalan Prof. Dr. Hamka, Jalan Khatib Sulaiman, dan Jalan Rasuna Said, Kota Padang

\begin{tabular}{|l|l|c|}
\hline No & \multicolumn{1}{|c|}{ Nama Jalan } & $\begin{array}{c}\text { Banyak } \\
\text { Pohon }\end{array}$ \\
\hline 1. & Jalan Prof. Dr. Hamka & 39 \\
\hline 2. & Jalan Khatib Sulaiman & 53 \\
\hline 3. & Jalan Rasuna Said & 65 \\
\hline
\end{tabular}

Sumber: Perhitungan menggunakan google earth, 2018

Pada tabel 10, pohon terbanyak berada disepanjang Jalan Rasuna Said, dan pohon terbanyak kedua berada di Jalan Khatib Sulaiman, dan pohon yang terbanyak ketiga yaitu Jalan Prof. Dr. Hamka. Pohon yang dihitung berjarak 200 meter dari titik pengambilan sampel, berdasarkan Peraturan Pemerintah RI (1999).

Setelah dianalisis dari hasil penelitian dilapangan, kepadatan tertinggi terjadi dihari Senin di ruas Jalan Khatib Sulaiman dengan total jumlah kendaraan sebesar 13125 unit kendaraan yang melewati jalan tersebut saat pagi dari jam 06.00 - 09.00 WIB, degan lebar ruas jalan yaitu 3,50 meter dan tipe ruas 4 lajur terbagi/1 arah sehingga bisa dilewati tiga mobil di satu jalur yang memiliki pembatas jalan.

Kepadatan terendah terjadi dihari Sabtu di ruas Jalan Khatib Sulaiman dengan total jumlah kendaraan sebesar 3826 unit kendaraan yang melewati jalan tersebut saat jam $08.01-09.00$
WIB. Berikut grafik tingkat kepadatan dari ketiga lokasi penelitian berdasarkan hari pengamatan, bisa dilihat pada gambar 2 berikut:

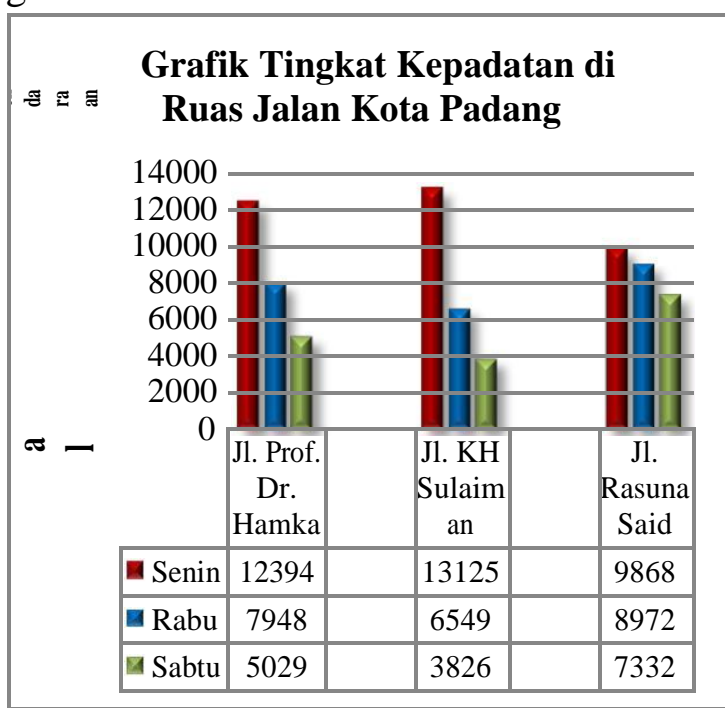

Gambar 2 : Grafik Tingkat Kepadatan

di Ruas Jalan Kota Padang

Sumber : Hasil Analisis, 2017

Pada gambar tersebut dapat dilihat ketika hari Senin ditiap lokasi penelitian lebih tinggi dibandingkan dengan hari Rabu dan Sabtu, dimana hari Senin merupakan waktu sibuk masyarakat untuk beraktifitas, anak-anak sekolah yang berangkat ke sekolah dan pegawai atau pekerja kantoran yang akan melalakukan upacara di lingkungan sekolah ataupun kantor di setiap pagi, menyebabkan masyarakat memulai aktifitas secara serentak sehingga jalan dipenuhi oleh kendaraan yang mengakibatkan kepadatan lalu lintas.

Pada hari Sabtu ditiap lokasi penelitian lebih rendah dibandingkan hari yang lain, ini disebabkan oleh kurangnya aktifitas masyarakat pada hari Sabtu disaat paginya, disebabkan oleh anak-anak sekolah pada hari tersebut sudah ada yang diliburkan, seperti sekolah swasta yang sudah menerapkan pelajar untuk libur pada 
hari Sabtu. Pegawai atau pekerja kantoran-pun juga diliburkan pada hari Sabtu dan Minggu, walaupun ada beberapa sekolah swasta dan kantor yang masih beraktifitas pada hari Sabtu.

Hasil analisis pencemaran udara paling tinggi berada di Jalan Simpang Tunggul Hitam pada hari Senin, dengan hasil pengukuran udaranya tidak sehat. Disebabkan oleh kendaraan dipagi hari lebih banyak yang keluar dari Simpang Tunggul Hitam, sedangkan kendaraan dari Tabing yang melewati Simpang Tunggul Hitam juga mengalami

kepadatan kendaraan, sehingga kendaraan bermotor menurunkan kecepatan kendaraan yang berdampak pada banyaknya polusi yang dihasilkan oleh kendaraan.

Jalan Simpang Tunggul Hitam juga dilintasi oleh kereta api, saat kereta api melintasi Jalan Simpang Tunggul Hitam kendaraan bermotor yang keluar masuk simpang akan otomatis berhenti dan menyebabkan kepadatan kendaraan meningkat.

Pencemaran udara paling rendah berada di Jalan Rasuna Said pada hari Sabtu dengan hasil pengukuran udara dalam kategori baik, dikarenakan di Jalan Rasuna Said memiliki pepohonan di sepanjang jalan sehingga, polusi yang dihasilkan kendaraan diserap oleh pohon-pohon yang berada di sekitar jalan tersebut. Berikut grafik indeks pencemaran udara rata - rata di ruas jalan Kota Padang dapat dilihat pada gambar 3 berikut:

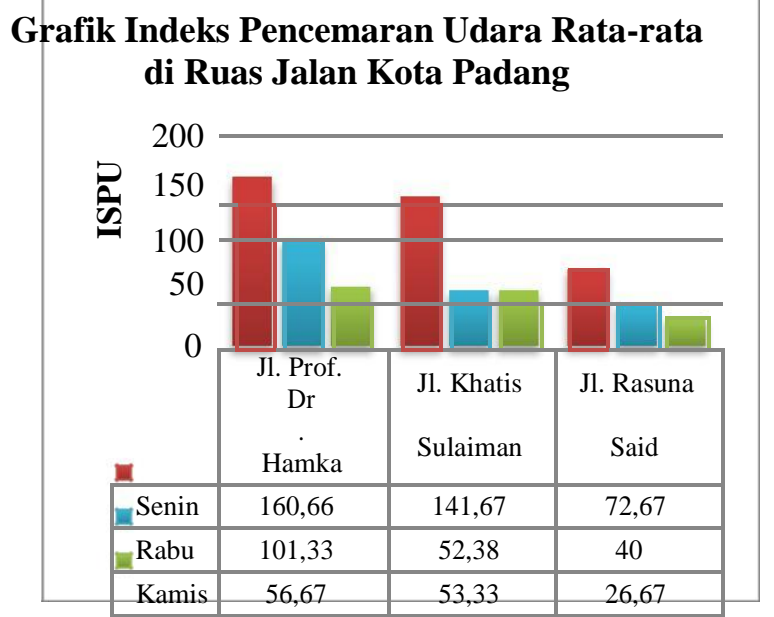

Gambar 3: Grafik Indeks Pencemaran Udara Rata-rata di Ruas Jalan Kota Padang

Sumber: Hasil Analisis, 2017

Pada gambar 4.17 tersebut dapat dilihat bahwa pencemaran udara yang selalu menurun dari hari Senin - Sabtu, dipengaruhi oleh banyaknya sisa hasil pembakaran kendaraan bermotor di udara yang berada dilokasi penelitian. Semakin padat kendaran yang berada di jalan maka, udara semakin tercemar.

Kendaraan yang melewati Jalan Prof. Dr. Hamka bisa mencapai 4131 kendaraan/jam, sehingga tiap kendaraan yang menghasilkan karbon monoksida tidak dapat diserap secara keseluruhan oleh pepohonan yang ada di sekitar Jalan Simpang Tunggul Hitam. Berikut Peta Kualitas Udara dikepadatan Lalu Lintas Kota Padang, bisa dilihat pada gambar 4 berikut: 


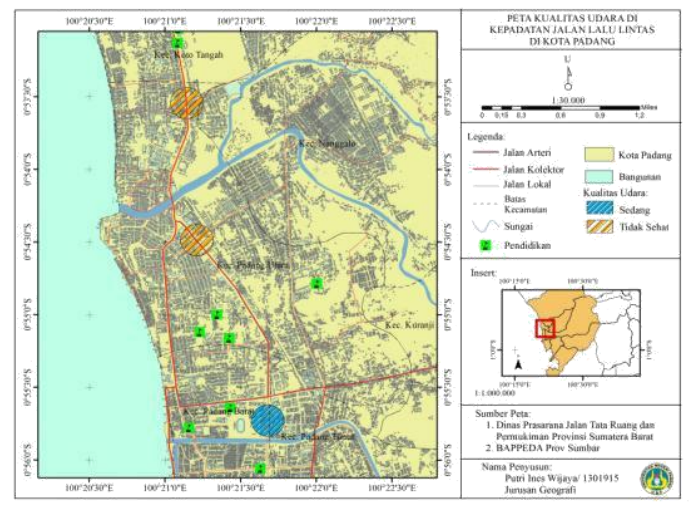

Gambar 4: Peta Kualitas Udara

dikepadatan Lalu Lintas Kota Padang

Gambar tersebut dibutuhkan peta

Kota Padang, peta kecamatan Kota Padang, peta jaringan jalan, peta bangunan penduduk, sungai, dan bangunan pendidikan. Hasil peta keseluruhan dapat dilihat bahwa pencemaran udara dengan kategori tidak sehat berada di Jalan Prof. Dr. Hamka dan Jalan Khatib Sulaiman, dan hasil udara yang belum tercemar berada di Jalan Rasuna Said. Dilihat pada bangunan yang terbanyak terkena udara yang tercemar berada di Jalan Prof. Dr. Hamka disekitar Simpang Tunggul Hitam.

Hasil penelitian ini menunjukkan bahwa kualitas udara dapat sangat bervariasi di dalam kota-bahkan dalam hitungan beberapa meter persegi. Artinya, dalam satu kota atau wilayah, kondisi dan kualitas udaranya bisa sangat bervariasi. Temuan yang tak terduga ini menunjukkan kemungkinan pihak berwenang setempat untuk menentukan titik-titik polusi yang telah masuk kategori tidak sehat bahkan ada yang termasuk kedalam kategori sangat tidak sehat dalam pengukuran perjam yang mungkin tidak terdeteksi sebelumnya oleh instansi terkait dan membantu warga menghindari tinggal di sana, atau berkegiatan di area tersebut pada waktu tertentu.

\section{PENUTUP}

\section{Simpulan}

a. Kepadatan kendaraan bermotor di Jalan Prof. Dr. Hamka terjadi pada hari Senin dengan jumlah 12394 unit kendaraan, dengan lebar ruas jalan 3,50 meter dan tipe ruas 4 lajur terbagi/1 arah sehingga bisa dilewati tiga mobil di satu jalur yang memiliki pembatas jalan.

Pada Jalan Khatib Sulaiman kepadatan tertinggi terjadi pada hari Senin dengan jumlah kendaraan sebesar 13125 unit kendaraan, dengan lebar ruas jalan 3,50 meter dan tipe ruas 4 lajur terbagi/1 arah sehingga bisa dilewati tiga mobil di satu jalur yang memiliki pembatas jalan.

Sedangkan di Jalan Rasuna Said kepadatan kendaraan bermotor terjadi pada hari Senin dengan jumlah kendaraan 9868 unit kendaraan dengan lebar ruas jalan 3,50 meter dan tipe ruas 4 lajur tak terbagi/1 arah sehingga hanya bisa dilewati dua mobil di satu jalur yang tidak memiliki pembatas jalan.

b. Volume karbon monoksida (CO) di Jalan Prof. Dr. Hamka termasuk kedalam kategori udara tidak sehat pada hari Senin, karena mempunyai kosentrasi sebesar 160,66 mg/m ${ }^{3}$, disebabkan oleh banyaknya kendaraan yang melewati jalan tersebut dengan kecepatan kendaraan yang lambat, dan tidak 
adanya pohon pelindung di sepanjang jalan tersebut.

Di Jalan Khatib Sulaiman volume $\mathrm{CO}$ termasuk kedalam kategori udara tidak sehat dengan konsentrasinya sebesar 141,67 $\mathrm{mg} / \mathrm{m}^{3}$ pada hari senin, disebabkan oleh sedikitnya pohon pelindung di sepanjang jalan dan masih ditumbuhi pohon kecil disepanjang jalan.

Sedangkan Jalan Rasuna Said volume $\mathrm{CO}$ termasuk kedalam kategori udara yang baik atau masih sehat dengan kosentrasinya 72,67 $\mathrm{mg} / \mathrm{m}^{3}$, disebabkan oleh banyaknya pepohonan di sepanjang jalan sehingga bisa membantu

menetralisasikan udara yang tercemar diakibatkan oleh hasil pembakaran mesin kendaraan yang tidak optimal.

\section{Saran}

a. Perlu dilaksanakan aturan yang tegas dan pengawasan yang ketat dari institusi terkait dan Pemerintah Kota Padang untuk mengurangi kepadatan kendaraan di jalan lalu lintas, dengan cara membagi atau mimisahkan waktu pelajar dan

pekerja kantoran memulai aktivitasnya, karena kepadatan tertinggi mulai terjadi saat pagi pukul 07.00 WIB.

b. Perlu dilaksanakan aturan yang tegas dan pengawasan yang ketat dari institusi terkait untuk menciptakan peningkatan kinerja dalam pengendalian pencemaran gas CO di Kota Padang, dengan menambahkan pohon pelindung disepanjang jalan Kota Padang.

c. Adanya kesadaran bagi masyarakat KotaPadangagardapat menimalisasikan pemakaian kendaraan bermotor sehingga dapat mengurangi kepadatan kendaraan dengan beralih menggunakan kendaraan umum seperti angkot ataupun bus TransPadang yang sudah lebih nyaman, dengan perubahan kecilpun dari masyarakat dapat mengurangi pencemaran udara terutama karbon monoksida.

\section{DAFTAR PUSTAKA}

BadanPengendalian Dampak Lingkungan. (1997). Perhitungan dan Pelaporan Informasi Indeks Standar Pencemaran Udara. No. 107/1997.

BPS Kota Padang. (2016). Kota padang dalam angka 2016.

Kepala Badan Dampak Lingkungan. (1997). Pengelolaan Lingkungan Hidup. No.107 tahun 1997

Menteri Lingkungan Hidup. (1997). Indeks Standar Pencemaran Udara (ISPU). KEP. 45 /MENLH/1997.

Peraturan Menteri Lingkungn Hidup. (2010). Pengendalian Pencemaran Udara di Daerah. No. 12/2010.

Peraturan Pemerintah RI. (1999). Pengendalian Pencemaran Udara. No. 41/1999

Sinulingga. B.D. (1999). Pembangunan Kota-Tinjauan Regional dan 
Lokal, Pustaka Sinar Harapan. Jakarta.

Sumadi. (2006). Kemacetan Lalulintas Pada Ruas Jalan Veteran Kota Breres. Teknik Pembangunan Daerah dan Kota. Semarang.
Tjahjono, T, 2007. Traffic Safety Evaluation for Lane Extention on Jagorawi Tol Road. Prosiding Konferensi Nasional Teknik Jalan 8, Jakarta 4-6 September 2007. 